\title{
Embolization Therapy in Pediatric Cardiology
}

\author{
ROBERT H. BEEKMAN, III, M.D., DAVID SHIM, M.D., and THOMAS R. LLOYD, M.D. \\ From the Division of Pediatric Cardiology, Department of Pediatrics, C.S. Mott Children's Hospital, University of Michigan, \\ Ann Arhor. Michigan
}

\begin{abstract}
Transcatheter embolization therapy has assumed an important role in the management of patients with congenital heart disease. A variety of embolization materials, most commonly steel coils, is available to treat or palliate patients with aortopulmonary collateral vessels or surgical shunts, arteriovenous malformations, and anomalous venovenous connections (rommon afier surgical intervention for the univentricular heart). At many centers, coil occlusion has recently become the treatment of choice for patients with a restrictive patent ductus arteriosus (PDA). This article describes the materials and techniques of embolization therapy, as well as the common indications encountered in the practice of pediatric interventional cardiology. (J Interven Cardiol 1995;8: 543-556)
\end{abstract}

\section{Introduction}

One of the earliest reported uses of transcatheter embolization therapy involved preoperative injection of melted paraffin into the carotid arteries of patients with head and neck tumors. ' Over the ensuing years, a variety of absorbable and nonabsorbable materials were developed and used for peripheral arterial embolization. It was not until Gianturco et al. ${ }^{2}$ introduced the occluding stainless steel coil in 1975, however, that transcatheter embolization became an important therapeutic procedure in pediatric cardiology. In 1995, transcatheter embolization techniques are used commonly to treat a variety of anomalous arterial and venous connections in children with congenital heart disease (Table 1). For example, embolization therapy is commonly applied to children with aortopulmonary collaterals before and after surgical repair of tetralogy of Fallot or pulmonary atresia with ventricular septal defect; surgical aortopulmonary shunts can also be closed by catheter techniques. Embolization techniques are also useful in patients with arteriovenous malformations (e.g., coronary or intrapulmonary), or anomalous venovenous communications (e.g., follow-

Address for reprints: Robert H. Beekman, III. M.D., University of Michigan Medical Center. 1500 E. Medical Center Drive, MCHC F1310. Box 0204, Ann Arbor, MI 48109. Fax: (313) 936-9470. ing the bidirectional Glenn or Fontan procedures). Recently, Gianturco steel coils have been effectively utilized to occlude the small-to-moderate sized patent ductus arteriosus. The early results suggest that this transcatheter technique may replace surgical ligation as the treatment of choice for this lesion. This article will discuss some of the current applications of transcatheter embolization therapy in pediatric interventional cardiology.

\section{Embolization Materials and Catheters}

The embolization materials available for use in the pediatric cardiac catheterization laboratory are listed in Table 2. The Gianturco stainless steel coil is perhaps the most frequently used device for embolization therapy in children. It was initially introduced for occlusion of large arterial vessels, but has been applied to a wide variety of anomalous arterial and venous connections. The current Gianturco coil (occluding spring emboli [Cook, Bloomington, IN, USA]) consists of a stainless steel coil to which Dacron strands have been applied in order to increase thrombogenicity. ${ }^{3}$ The coil comes in a variely of lengths and helical diameters, and can be delivered through a 4 or $5 \mathrm{Fr}$ catheter. When used to occlude arterial or venous collateral vessels, a coil is generally chosen whose helical diameter is 


\section{BEEKMAN, ET AL.}

Table 1. Specific Applications of Embolization Therapy in Pediatric Cardiology

Aortopulmonary collateral arteries

Surgical aortopulmonary shunts

Anomalous arteriovenous and venovenous connections

Patent ductus arteriosus

Bleeding vessels
$20 \%-30 \%$ larger than the diameter of the vessel to be occluded. It is important to note that the technique of PDA coil occlusion differs substantially, and will be described below. The Gianturco coil causes vascular occlusion by inducing the formation of a thrombus, which subsequently organizes. ${ }^{4}$ Experimental studies have shown that systemic heparinization does not inhibit this process. ${ }^{5}$

Other materials that are used in pediatric embolization include platinum microcoils, Gelfoam, Ivalon, detachable balloons, and other devices. Platinum microcoils (Target Therapeutics, Santa Monica, CA, USA) are substanlially smaller than Gianturco coils and can be delivered through small catheters, such as the Tracker-18 (Target Therapeutics,), to occlude very small vessels subselectively. Platinum microcoils are available in a variety of sizes and shapes. Platinum is highly thrombogenic, and results in prompt thrombotic occlusion of small arterial and venous vessels. Gelfoam (Upjohn, Kalamazoo, MI, USA) is a gelatin sponge that can be cut into small pledgets for vascular occlusion. The small Gelfoam pieces are mixed with dilute contrast, loaded into a syringe, and washed through a catheter whose tip is placed selectively in the vascular structure to be occluded. Because Gelfoam is not radio-opaque, it is imperative to avoid reflux of the contrast out of the vessel to be embolized. Gelfoam results in vascular occlusion by inducing thrombosis, but because the gelatin sponge is biodegradable, recanalization may occur. Permanent vascular occlusion, therefore, may require the combined use of Gelfoam with stainless steel or platinum coils. Ivalon (Interven-

Table 2. Embolization Materials Used in Pediatric Cardiology

Steel Gianturco coils

Platinum microcoils

Gelfoam

Ivalon particles

Detachable balloons and other devices tional Therapeutics, Inc., Fremont, CA, USA) is an inert polyvinyl alcohol available as a coarse powder with particle diameters ranging from $150-1,000 \mathrm{mi}-$ crons; it is most commonly used to occlude small bleeding vessels. Ivalon is typically mixed with contrast and delivered as a slurry in a syringe. The delivery catheter must be positioned well into the vessel to be occluded, and care taken to assure that the Ivalon contrast slurry does not reflux into the more proximal vascular bed. Ivalon results in local vascular inflammation, and thrombus formation with occlusion. Recanalization does not occur, as Ivalon is not biodegradable. ${ }^{6}$ Detachable balloons, the Rashkind PDA occluder (USCI, C.R. Bard, Inc., Billerica, MA, USA), and the Clamshell occluder (USCI, C.R. Bard, Inc.) are other devices which have been used to occlude large vascular communications. None of these devices is currently commercially available in the United States.

Several different catheters are available to deliver embolization therapy in pediatrics. Embolization materials, of course, are implanted through end-hole delivery catheters. It is essential that the catheter position be confirmed by angiography prior to embolization. Balloon-tipped end-hole catheters are often helpful in securing the catheter position, and preventing reflux of material proximally. Catheters with configurations designed for selective vascular catheterization, such as the Judkins right coronary, cobra, and headhunter catheters, may facilitate selective arterial and venous catheterization prior to embolization. Hydrophilic coated catheters can be very helpful in selective catheterization of small or tortuous vessels. Hydrophilic catheters which accept a 0.038 -inch guidewire; however, they should be used to deliver coils no larger than 0.035 -inch in diameter, because larger coils can become trapped within these catheters. We have also found the Tracker-18 catheter (Target Therapeutics,) to be extremely helpful in subselectively catheterizing and embolizing small vessels, including coronary artery fistulae. The Tracker-18 is a 3Fr catheter that can be introduced coaxially through a $5 \mathrm{Fr}$ end-hole catheter (e.g., a right coronary catheter).

\section{General Method of Arterial or Venous Embolization}

Pediatric embolization therapy demands more of a cardiologist than the technical skills required for selec- 
tive vascular catheterization and embolization in children. To perform these procedures safely and effectively, the operator must also have a detailed understanding of the relevant normal and abnormal vascular anatomy, the natural and unnatural history of the lesion, and the physiological consequences and potential complications of intervention. If the embolization procedure is part of a staged multidisciplinary approach to a complex cardiac defect, then close collaboration with a pediatric cardiac surgeon is mandatory. Finally, although a pediatric cardiologist may possess the technical skills necessary to perform an embolization, in some cases it is prudent to refer the patient to another subspecialist (e.g., an interventional neuroradiologist), or to at least involve another subspecialist (e.g., adult cardiologist, interventional radiologist) in the procedure.

The precise method utilized for a therapeutic embolization procedure depends upon the individual circumstances of the case, including both patient size, and the nature of the vessel or malformation to be occluded. The general approach utilized in our laboratory is outlined here. A vascular sheath is always used to introduce the angiographic and embolization catheters. The sheath enables one to perform multiple catheter exchanges, and to withdraw partially delivered or undelivered coils without relinquishing vascular access. Once the appropriate access is achieved, the patient is heparinized. Activated clotting times are monitored intermittently, and kept between 250 and 300 seconds throughout the case. Selective angiography is essential to accurately delineate the vascular anatomy prior to embolization. When the embolization catheter is introduced into the target vessel, a small volume contrast injection is performed to provide positive identification of the vessel to be occluded. The contrast is then flushed from the catheter prior to coil delivery, as fluoroscopic visualization of a small coil may be difficult in a contrast filled delivery catheter. For anomalous arterial or venous vessels, a coil is generally chosen whose helical diameter is $20 \%-30 \%$ larger than the collateral vessel itself. We do not soak the coil in topical thrombin prior to embolization. The coil is advanced through the delivery catheter to the collateral using a flexible wire that does not straighten the delivery catheter at its distal bend. If there is concern that the pushing wire may straighten the catheter, then the wire is gently advanced through the catheter without a coil, to document that it does not displace the catheter tip from the target vessel. Approximately 5-10 minutes after coil delivery, a repeat angiogram is performed. If vascular patency requires additional coils, at times they can be implanted in combination with Gelfoam pledgets.

\section{Specific Applications of Embolization Therapy}

Aortopulmonary Collateral Arteries. Aortopulmonary collaterals are a common source of accessory
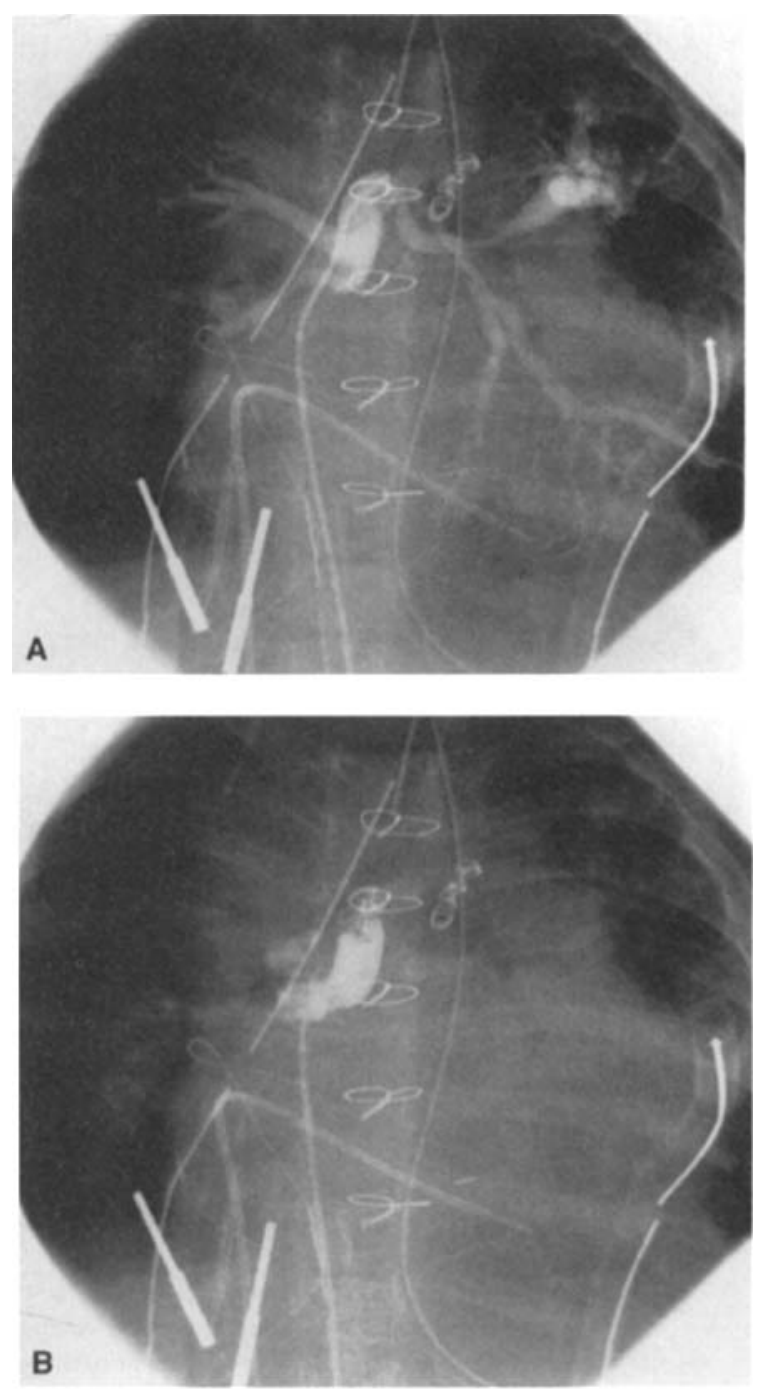

Figure 1. (A) Selective angiography demonstrates a large aortopulmonary collateral artery supplying branches of both pulmonary arteries in a 22-month-old infant with pulmonary atresia and ventricular septal defect. (B) The aortopulmonary collateral has been completely occluded with multiple Giantures coils. Coils are also evident in a second aortopulmonary collateral to the left upper lobe pulmonary artery 
BEEKMAN, ET AL.
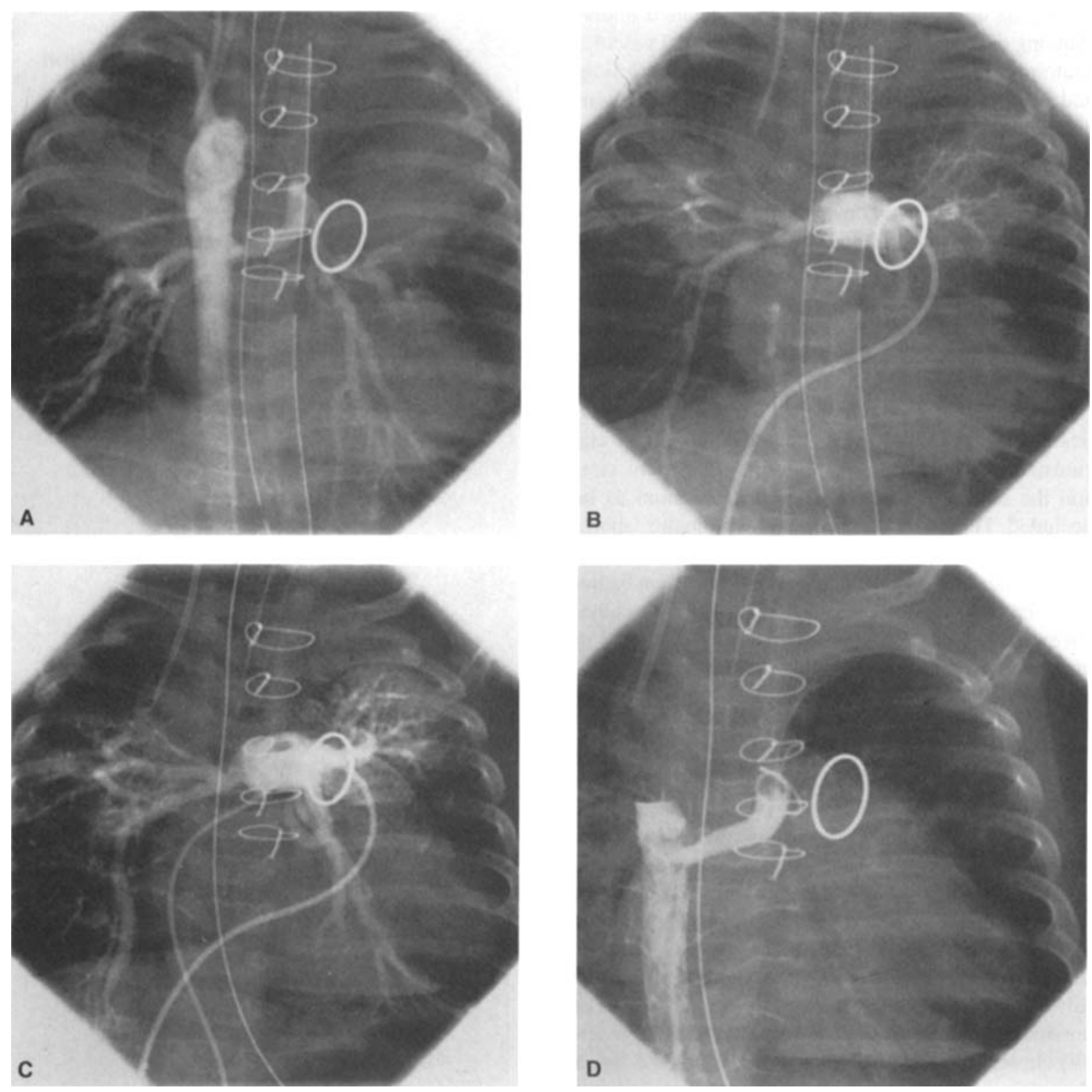

Figure 2. (A) Descending aortogram in a 5-month-old child with pulmonary atresia and ventricular septal defect following insertion of a right ventricle to pulmonary artery conduit. A large aortopulmonary collateral provides flow to both left and right lower lobe pulmonary arteries. (B) An angiogram performed in the conduit demonstrates flow to both central pulmonary arteries. Unobstructed flow from the central pulmonary artery to the lower left pulmonary artery is not evident, because of washout from the large aortopulmonary collateral. (C) The conduit angiogram is repeated with simultaneous balloon occlusion of the aortopulmonary collateral vessel. The continuity between the central and lower left pulmonary artery is now clearly evident and dual supply, therefore, documented. (D) The aortopulmonary collateral has been occluded with a Gianturco coil. 


\section{EMBOLIZATION THERAPY}

pulmonary blood flow in children with cyanotic congenital heart disease. These collateral vessels are particularly common in children with tetralogy of Fallot or pulmonary atresia with ventricular septal defect. Coil embolization of such vessels plays a key role in the coordinated surgical and medical approach to children with these complex lesions. ${ }^{7-10}$ Embolization of aortopulmonary collaterals is an essential step in a unifocalization strategy, and can be physiologically beneficial both preoperatively and postoperatively by diminishing total pulmonary blood flow and reducing the associated ventricular volume overload (Fig. 1). Prior to occluding an aortopulmonary collateral, one must be certain of two issues: (1) that the pulmonary blood flow provided by the collateral is not required for adequate systemic arterial oxygenation. The physiologic importance of the collateral flow can be assessed by temporarily balloon occluding the collateral vessel and observing any consequent changes in arterial oxygen saturation; and (2) that a dual arterial supply exists from the central pulmonary arteries to that segment of the lung. Dual supply can be assessed by performing a central pulmonary artery angiogram (typically via a right ventricle to pulmonary conduit) while the aortopulmonary collateral is balloon occluded. This technique avoids washout of the pulmonary artery segment of interest by unopacified blood entering from the collateral (Fig. 2). If dual arterial supply is not present, then the collateral may need to be incorporated into a surgical unifocalization procedure rather than being embolized.

The largest series describing coil embolization of aortopulmonary collateral vessels was reported by Perry and colleagues in $1989 .{ }^{7}$ Fifty-eight aortopulmonary collaterals were embolized in 36 patients ranging in age from 3 months to 23 years, the majority of whom had tetralogy of Fallot or pulmonary atresia with ventricular septal defect. Gianturco coils of wire diameter 0.025-0.038 inch, helical diameter 2-12 $\mathrm{mm}$, and length $2-5 \mathrm{~cm}$ were utilized. Coils were chosen to be $10 \%-40 \%$ larger in diameter than the vessel to be occluded. One to eight coils were implanted in each collateral vessel. Forty-two of the 58 collaterals were completely occluded; occlusion was described as "subtotal" in 14 vessels and partial in 1. A follow-up angiogram was performed for 25 vessels 9.5 months following coil embolization. Recanalization was observed in 1 of 18 completely occluded vessels, while 4 collaterals with trivial residual flow immediately following embolization were totally occluded at followup. Complications of coil embolization noted in this series included two patients with an aortopulmonary collateral in whom a coil embolized to a distal lower lobe pulmonary artery and was not retrieved. In each case, pulmonary angiograms documented vessel patency beyond the embolized coil. No patient had clinical evidence of pulmonary embolism. In another patient, a coil became dislodged and embolized to the descending aorta. This was retrieved by a snare catheter and removed from the femoral artery by cutdown.

It has become apparent in recent years that aortopulmonary collateral vessels occur commonly in patients with a univentricular heart who have undergone surgical palliation with a bidirectional Glenn shunt or a modified Fontan procedure. ${ }^{1}$ In these patients, the aortopulmonary collaterals most often arise from the subclavian arteries or their branches, particularly ipsilateral to a previous Blalock-Taussig shunt if one has been performed (Fig. 3). Such aortopulmonary collaterals provide an arterial source of pulmonary blood flow which may be competitive with the venous pulmonary flow provided by the cavopulmonary connection. We, and others, have been aggressive in using embolization techniques to eliminate aortopulmonary

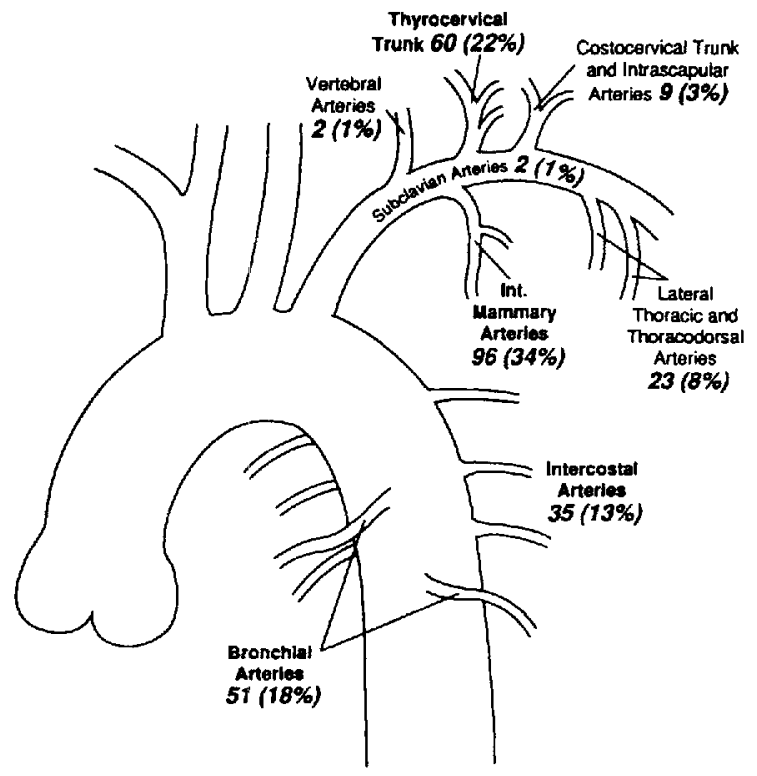

Figure 3. Diagram illustrating the sites of origin of aortopulmonary collateral vessels in 71 patients following either a Fontan procedure or a bidirectional Glenn shunt. The majority of collateral vessels arise from branches of the subclavian artery, particularly the internal mammary artery. (Reproduced with permission of The American College of Cardiology. ") 

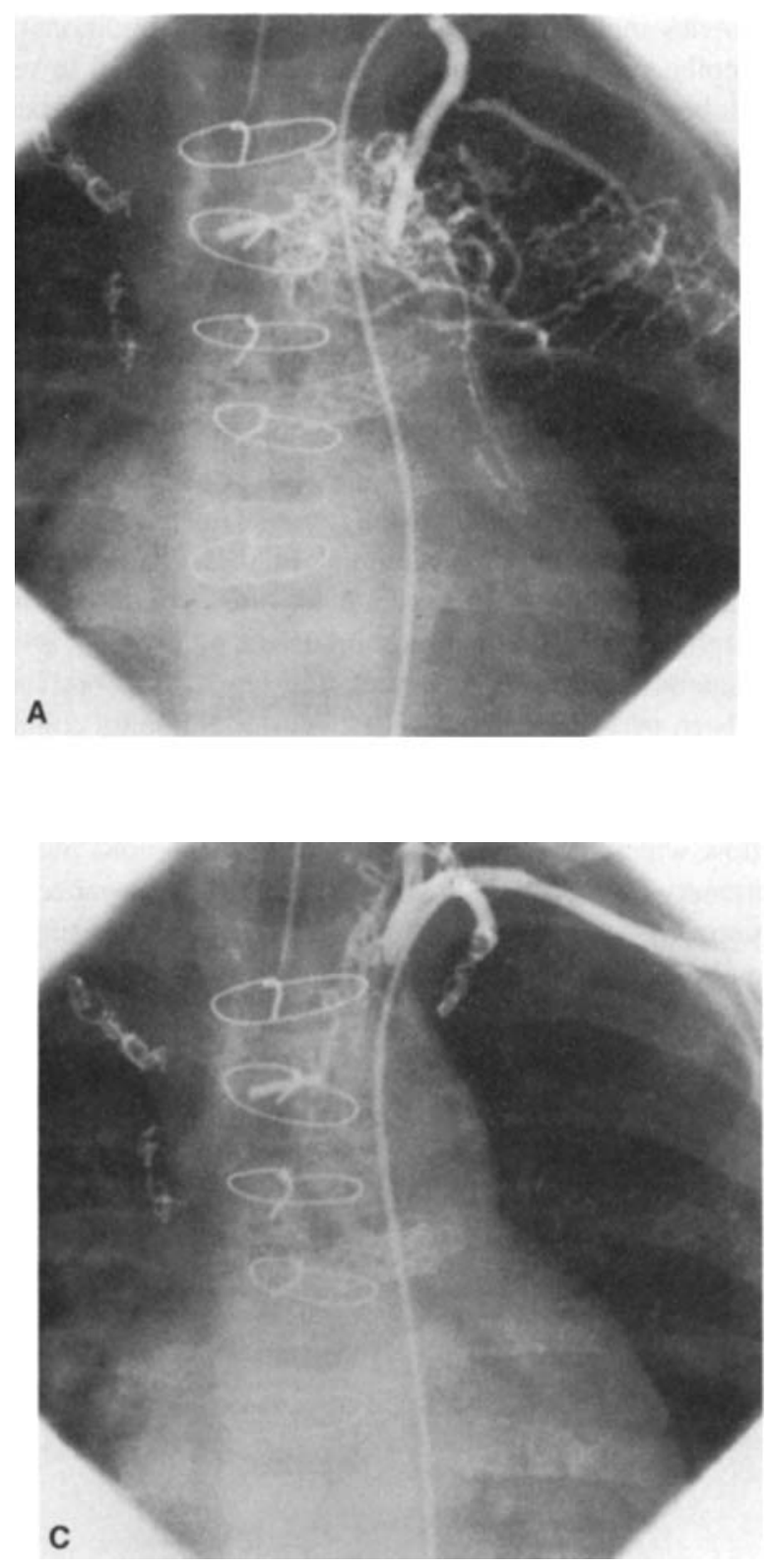

collateral vessels in these patients (Fig. 4). Although some children have shown clinical improvement after collateral embolization (e.g., diminished pleural effusions), there are no clinical trials clearly documenting the hemodynamic or clinical consequences of aortopulmonary collaterals in this patient population.

Surgical Aortopulmonary Shunts. Blalock-Taussig shunts can be occluded by transcatheter techniques when they are no longer needed to provide pulmonary blood flow (e.g., in a child with critical pulmonary stenosis when right ventricular compliance improves

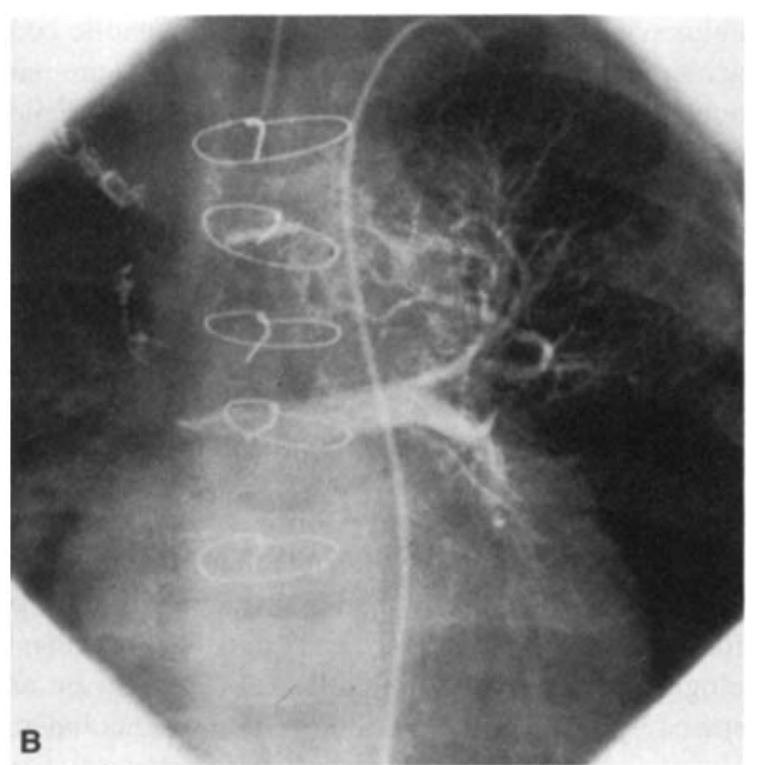

Figure 4. (A) Left internal mammary artery angiogram in a 6month-old infant with hypoplastic left heart syndrome following the Norwood and bidirectional Glenn procedures. Multiple aortopulmonary collateral vessels arise from the internal mammary artery. (B) A later frame demonstrates that collateral flow densely opacifies the stented central pulmonary artery. (C) After coil occlusion, no residual antegrade flow is evident in the internal mammary artery. A small residual collateral arises from the left thyrocervical trunk. The right internal mammary artery has also been coil embolized.

after balloon dilation) or if the shunt remains patent following surgical ligation. ${ }^{7-10,12}$ The classic or modified Blalock shunt can be embolized, but in either case some degree of stenosis is required to anchor the coil (or balloon) within the shunt (Figs. 5 and 6). Perry et al. $^{7}$ described coil embolization procedures in 14 patients with a Blalock-Taussig shunt ( 7 classic and 7 modified with a 3 - to $4-\mathrm{mm}$ Goretex conduit). Occlusion was described as complete in 6 patients, incomplete in 7 ( 1 intentional), and unsuccessful in 1 patient. Coils embolized to distal pulmonary arteries in three 


\section{FMBOLIZATION THERAPY}
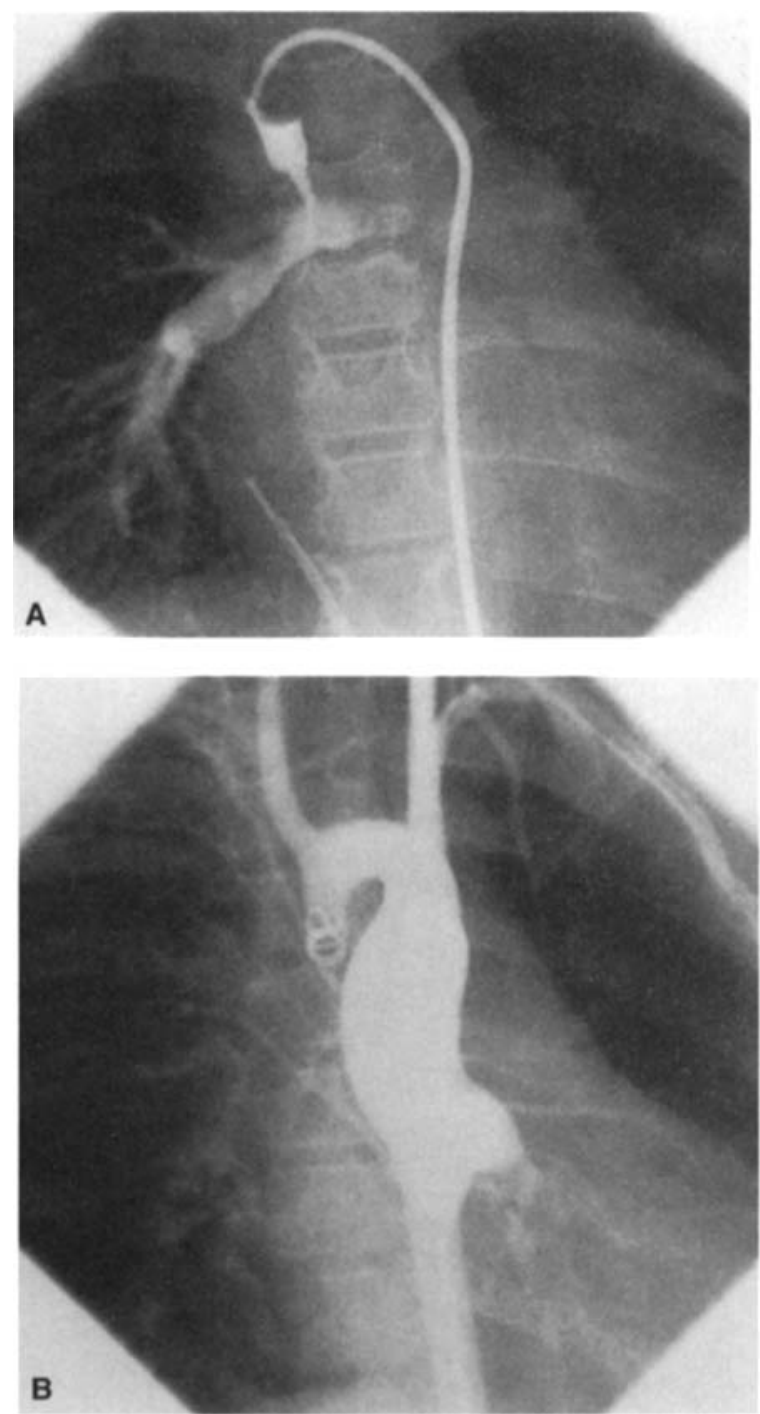

Figure 5. (A) Selective angiography demonstrates a classic right Blalock-Taussig shunt in a 5-year-old girl with pulmonary atresia and intact ventricular septum, who had undergone right ventricular outflow tract reconstruction and whose shunt was no longer necessary. (B) After coil embolization the Blalock-Taussig shunt is completely occluded.

cases. Thus, surgical shunts appear to have a higher incidence of residual flow and coil embolization to the pulmonary arteries after transcatheter occlusion, compared to aortopulmonary collaterals, presumably because of the variable degree of stenosis and the high flow velocity within these shunts.

Anomalous Arteriovenous and Venovenous Connections. Anomalous arteriovenous connections amenable to embolization therapy include coronary, intra- pulmonary, intrahepatic, and intracerebral arteriovenous malformations. Coronary artery fistulae arise from the left or right coronary artery and communicate to the right atrium, right ventricle or pulmonary artery. Untreated, these arteriovenous connections can be responsible for a sizable left-to-right shunt, coronary
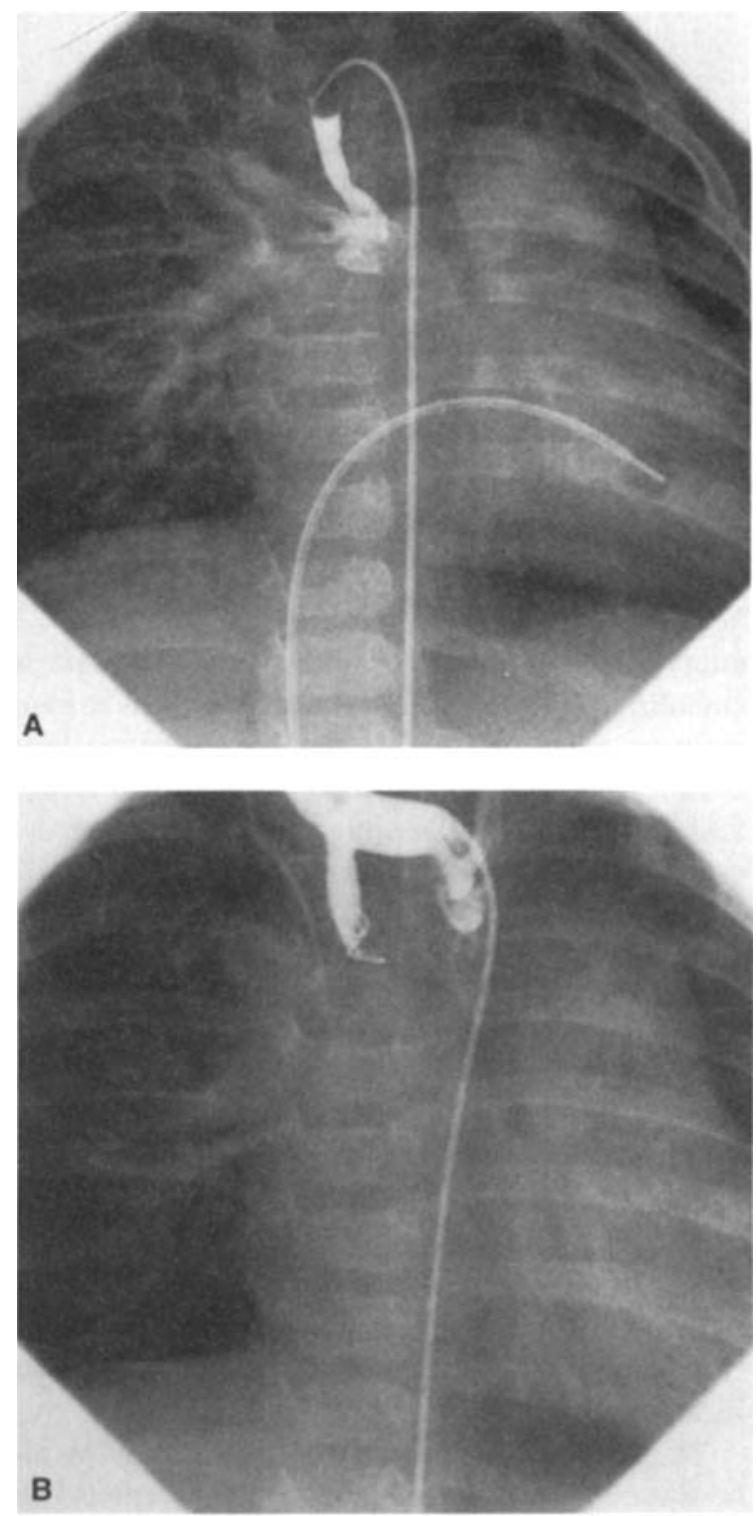

Figure 6. (A) Selective angiography demonstrates a modified right Blalock-Taussig shunt in a 9-month-old infant who had undergone balloon vilvuloplasty for critical pulmonary stenosis as a newborn. (B) After coil embolization the Blalock-Taussig shunt is completely occluded. 

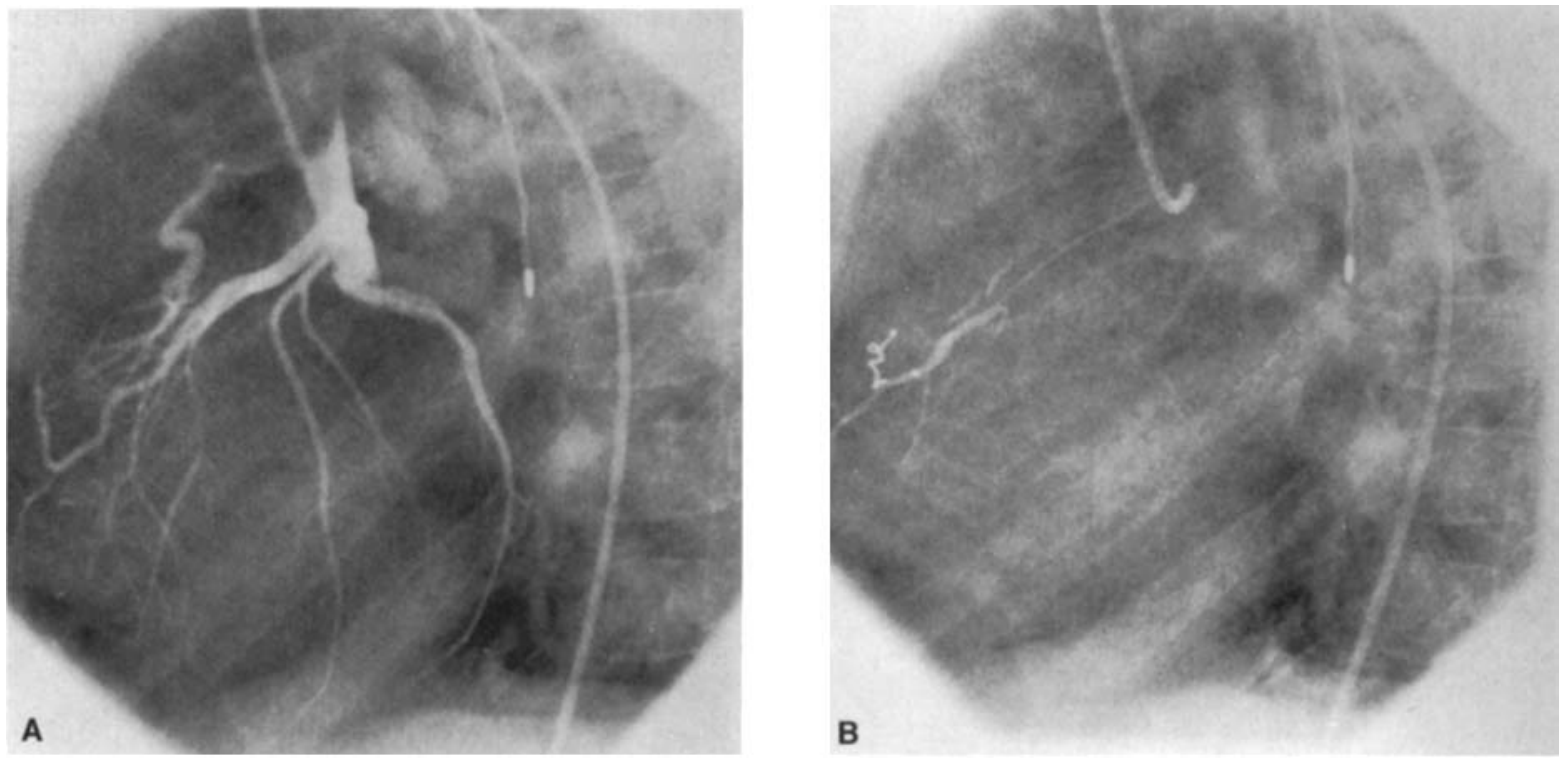

Figure 7. (A) Left coronary artery angiogram in a 6-year-old boy demonstrates a coronary artery fistula arising from the left anterior descending artery and communicating with the main pulmonary artery. (B) A platinum microcoil has been implanted in the fistula, delivered through a Tracker- 18 catheter introduced coaxially through a $5 \mathrm{Fr}$ coronary catheter.

artery steal, and infective endocarditis. Transcatheter embolization techniques are available to treat many coronary artery fistulae, ${ }^{13-15}$ and have been most successful in fistulae with a single large arterial feeding vessel; coronary fistulae with multiple arterial feeders can be more difficult to occlude completely. Embolization of coronary artery fistulae has most often been performed transarterially, utilizing Gianturco or platinum microcoils (Fig. 7). The transvenous route, and use of detachable balloons and other devices, has also been described for larger coronary fistulae. The combined series of Reidy et al. ${ }^{13}$ and Perry et al. ${ }^{14}$ report a total of 16 patients in whom 14 embolization resulted in complete fistula occlusion. One patient had a small residual shunt, and in another, a detachable balloon deflated and embolized to the pulmonary artery. No patient had evidence of myocardial ischemia related to the procedure, and late follow-up documented no cases of recanalization after successful fistula occlusion.

Transcatheter embolization techniques have also been used to treat intrapulmonary arteriovenous fistulae, ${ }^{10,16,17}$ hereditary or acquired, following a Glenn or Fontan operation (Fig. 8). Whitc and colleagues ${ }^{16}$ reported embolization of 276 intrapulmonary artcriovenous malformations in 76 patients (the majority with hereditary hemorrhagic telangiectasia), using detacha-

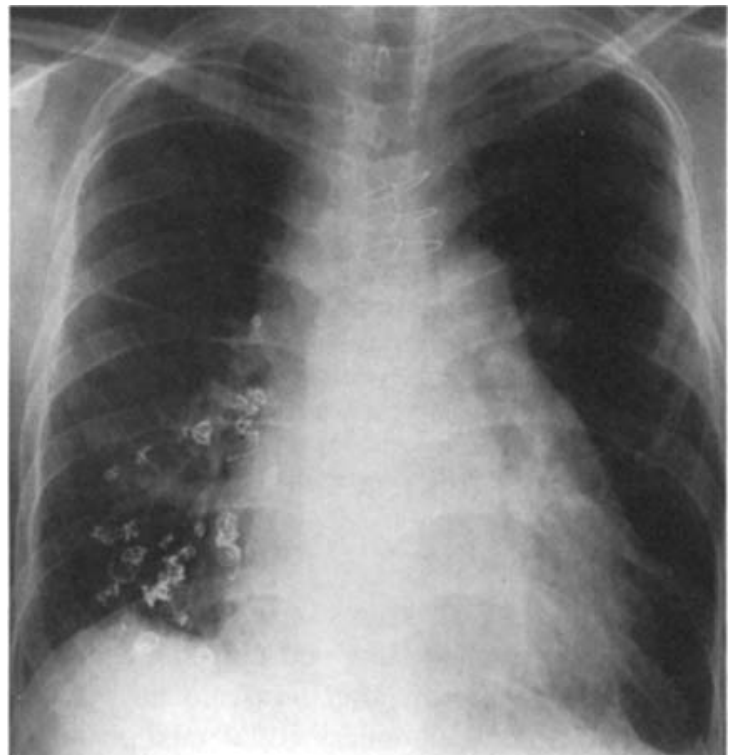

Figure 8. Chest $X$ ray in a patient with multiple right-sided intrapulmonary arteriovenous fistulae following a classic Glenn operation. After implantation of multiple Gianturco coils, the patient's arterial saturation increased from $78 \%-94 \%$. 
ble balloons with or without concurrent coils. Embolization therapy reduced the right-to-left intrapulmonary shunt and improved the degree of arterial hypoxemia; clinical improvement remained stable for at least 5 years. Systemic arteriovenous malformations involving the liver or the vein of Galen are also amenable to embolization therapy. ${ }^{18-20}$ Because of the complex nature of these vascular malformations, and the risk of embolization-induced hepatic or central nervous system damage, therapeutic interventions are best designed as collaborative efforts involving interventional radiologists and neuroradiologists (Fig. 9).

Anomalous venovenous connections have recently been recognized as an important cause of right-to-left shunting, diminished pulmonary blood flow, and progressive hypoxemia in children with a univentricular heart after a bidirectional Glenn shunt or a Fontan procedure. These vascular communications are amenable to transcatheter embolization with coils or other devices. In patients with a bidirectional Glenn shunt, for example, the superior vena cava may be decompressed into the inferior vena cava by the azygous vein, the hemiazygous vein, or by other anomalous venous channels (Fig. 10). After completion of a Fontan procedure, pulmonary blood flow may be compromised by development of venous communications between the inferior vena cava and the pulmonary venous atrium or a left-sided coronary sinus. If the hepatic

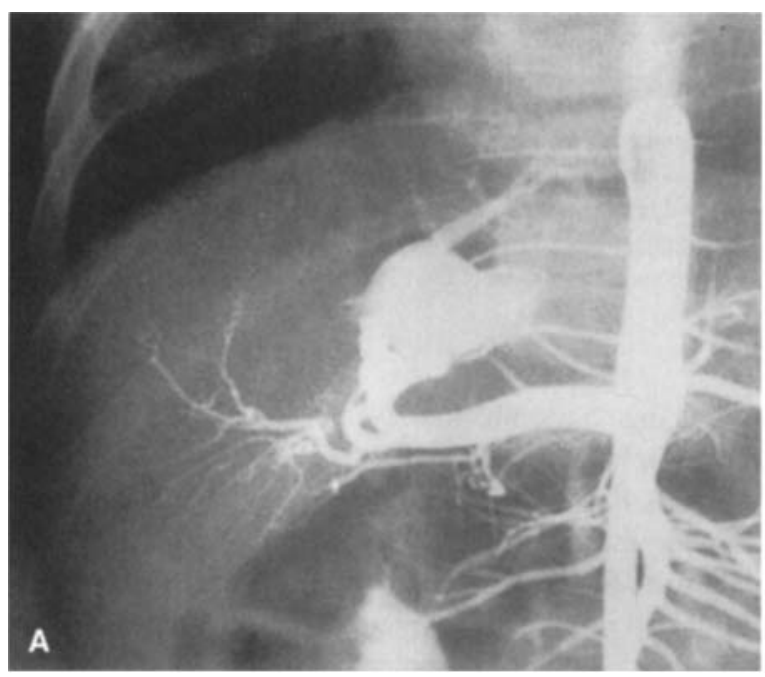

veins are excluded from the Fontan circuit and instead drain to the pulmonary venous atrium (c.g., the Kawashima operation), then venovenous collaterals commonly develop. These anomalous venous vessels decompress the higher pressure vena cava into the hepatic veins, may dilate progressively with time, and may be responsible for progressive arterial hypoxemia (Fig. 11). Transcatheter management of such unusual sites of right-to-left shunting can provide gratifying clinical improvement in some children.

Patent Ductus Arteriosus. Coil embolization is an effective transcatheter therapy for the small-to-moderate, restrictive PDA. ${ }^{21-23}$ Since the technique was first described in 1992, over 350 cases have been reported to the PDA Coil Registry. The procedure involves the use of a Gianturco coil with a helical diameter 2-3 times larger than the narrowest diameter of the ductus, and with length sufficient to provide 3-4 loops of coil after delivery (Fig. 12). The method of coil delivery differs substantially from that used to embolize tapering aortopulmonary collateral vessels (Fig. 13). First, the PDA is crossed with a $4-5 \mathrm{Fr}$ end-hole catheter (we typically use a Judkins right coronary catheter). With the catheter tip in the main pulmonary artery, two-thirds to one complete loop of coil is extruded from the catheter. The delivery catheter is then gently withdrawn into the aorta, noting the point at which the distal coil loop lodges within the PDA. The catheter

Figure 9. (A) A descending aortogram demonstrates a large intrahepatic arteriovenous malformation in an 8-month-old infant in congestive heart failure. (B) In concert with an interventional vascular radiologist, the intrahepatic arteriovenous malformation was embolized with Gelfoam. A selective hepatic arteriogram demonstrates very little residual shunting. 


\section{BEEKMAN, ET AL.}
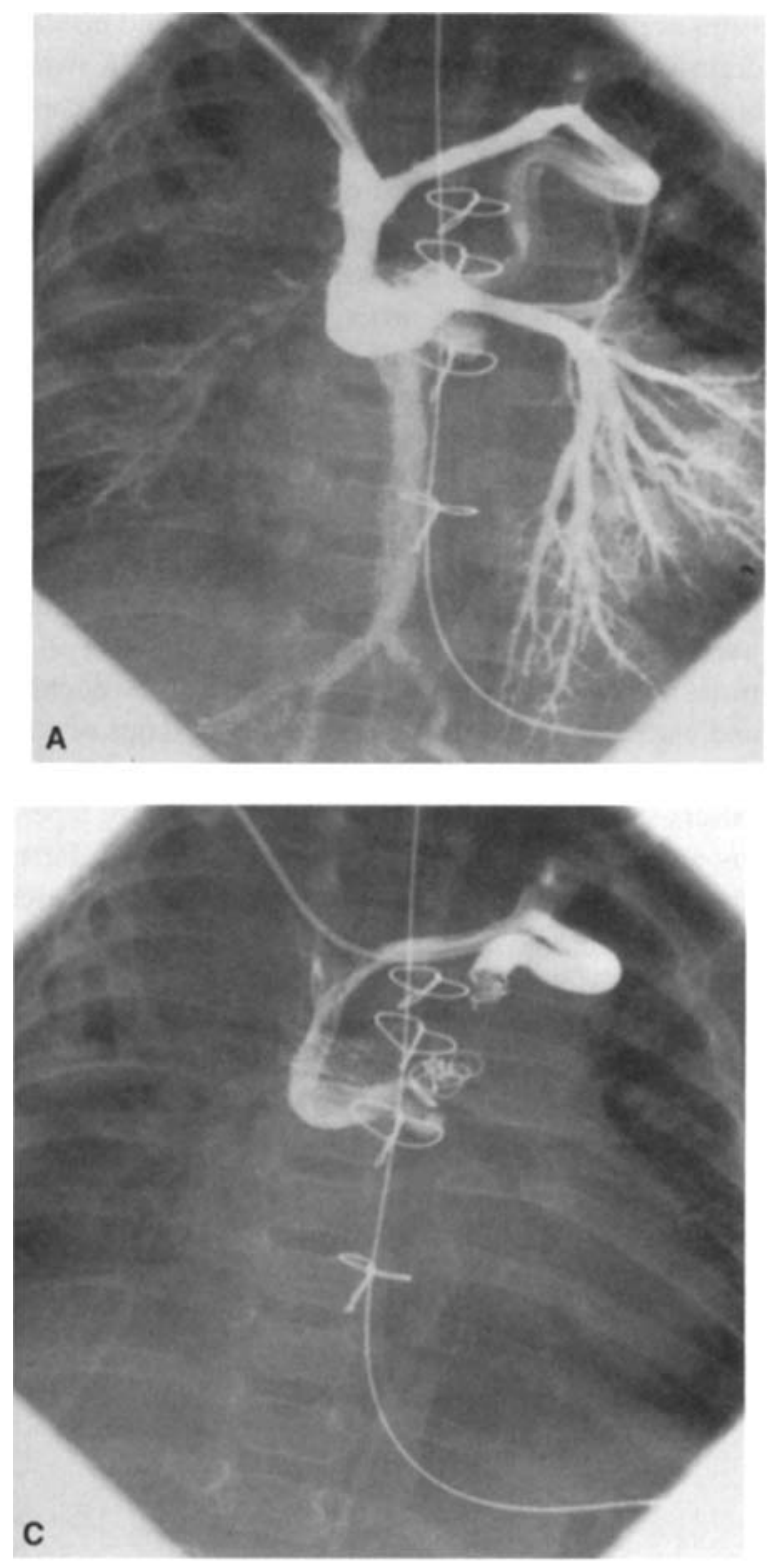

is then further withdrawn off of the remaining coil, releasing the 2-3 proximal loops within the aorta; the intrinsic elasticity of the Gianturco coil causes these loops to seat themselves within the aortic ampulla. If residual shunting is evident by angiography $10-15$ minutes later, a second coil (often smaller than the first) may be carefully placed across the PDA. In our experience, however, trivial residual shunts close spontaneously with a high frequency.

Between October 1992 and August 1994, 50 pa-

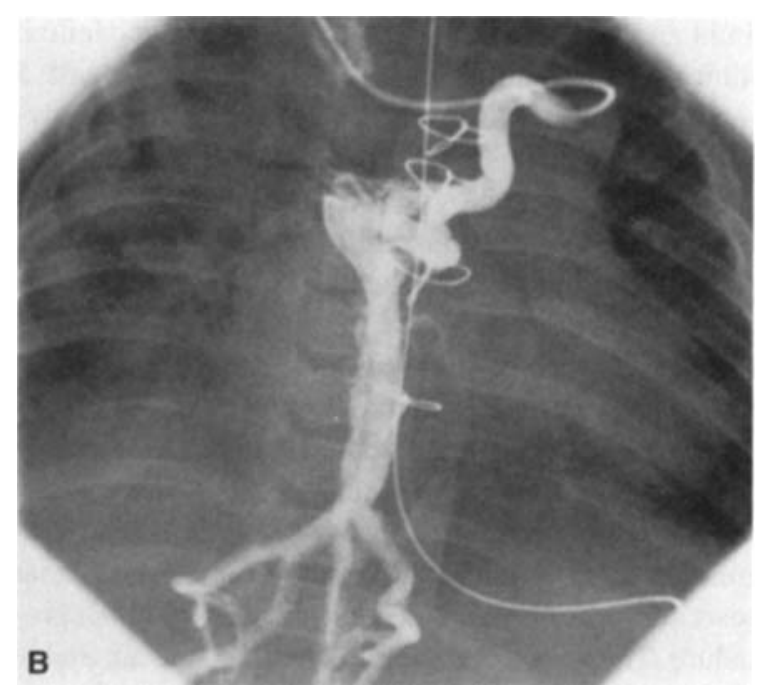

Figure 10. (A) Right superior vena cava angiogram in a 6-monthold infant with univentricular heart following a bidirectional Glenn shunt. A large venovenous collateral arises from the innominate vein and communicates with the azygous vein. (B) Selective angiogram in the anomalous venovenous collateral demonstrates substantial venous flow into the azygous vein. The collateral venous flow resulted in diminished total pulmonary blood flow and marked arterial hypoxemia. (C) After coil embolization there is no residual venovenous shunt flow evident.

tients (age 5 months to 62 years) underwent Gianturco coil implantation for a PDA at our institution. ${ }^{24} \mathrm{All}$ patients had a restrictive PDA with the minimum diameter ranging from $0.5-3.3 \mathrm{~mm}$ (mean $1.6 \mathrm{~mm}$ ). These patients have been followed for 1-20 months after coil implantation (mean 8 months), with residual shunting evaluated by color flow Doppler studies. Immediately after coil implantation, PDA occlusion was complete in 29 patients (58\%). Small residual shunts resolved spontaneously during follow-up in another 


\section{EMBOLIZATION THERAPY}
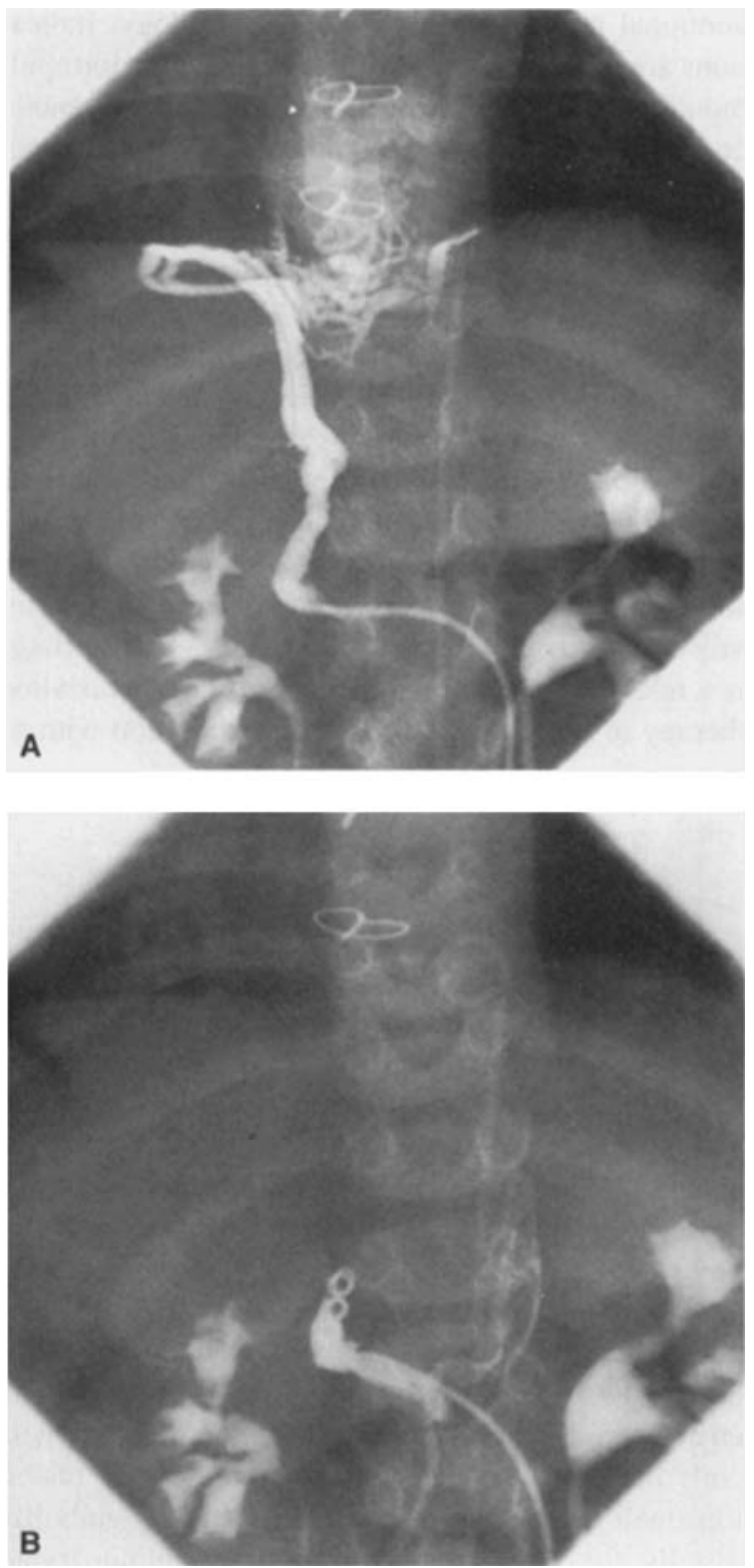

Figure 11. (A) Selective angiography demonstrates a venovenous collateral in a 3-year-old child following a Fontan procedure for univentricular heart and situs inversus with azygous continuation of an interrupted inferior vena cava. The venous collateral communicates from the inferior vena cava to the hepatic veins (which had been excluded from the Fontan circuit) and pulmonary venous atrium. (B) The venovenous collateral has been completely occluded by two Gianturco coils.
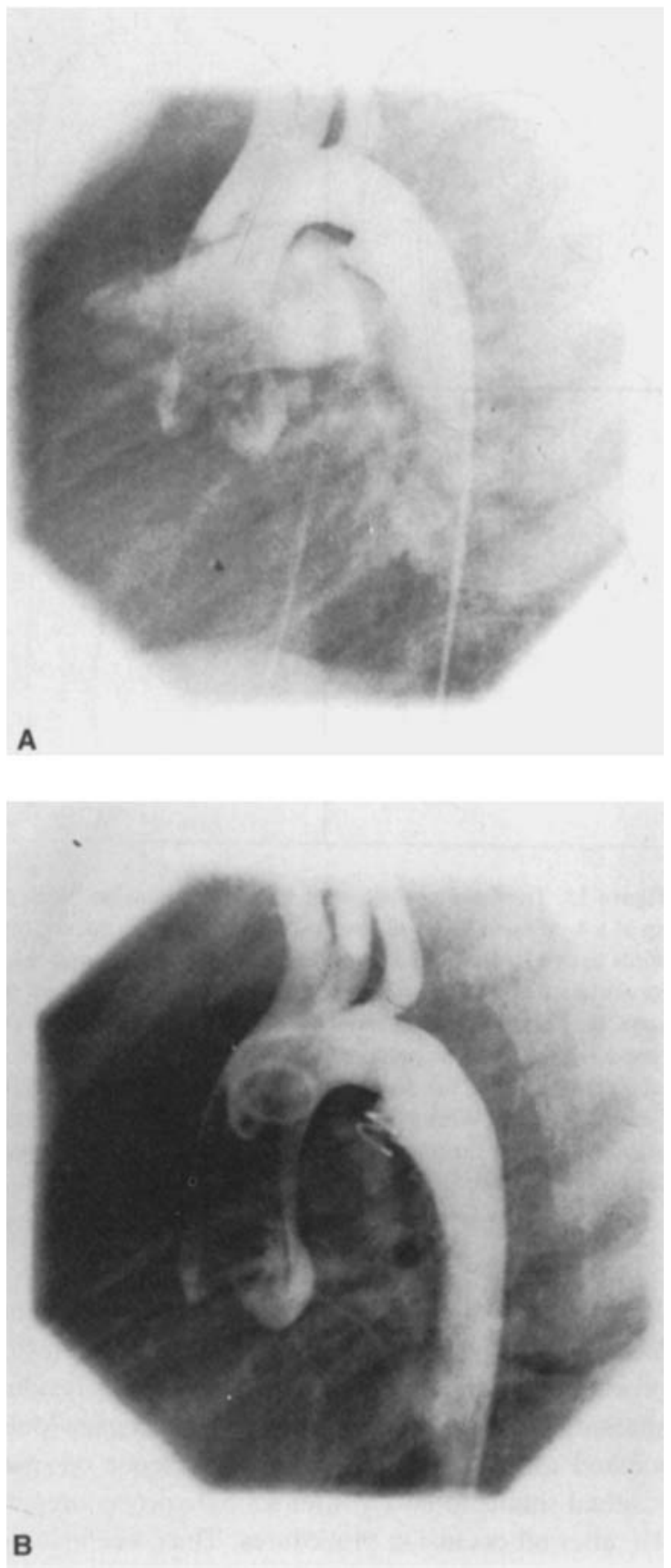

Figure 12. (A) Lateral aortogram in a 3-year-old girl demonstrates a moderate $\mathrm{PD} \Lambda$. The ductus diameter measured $2.5 \mathrm{~mm}$ at its narrowest point. (B) The ductus was completely occluded with a 0.038 inch, 5-mm diameter, 5-cm length Gianturco coil. 


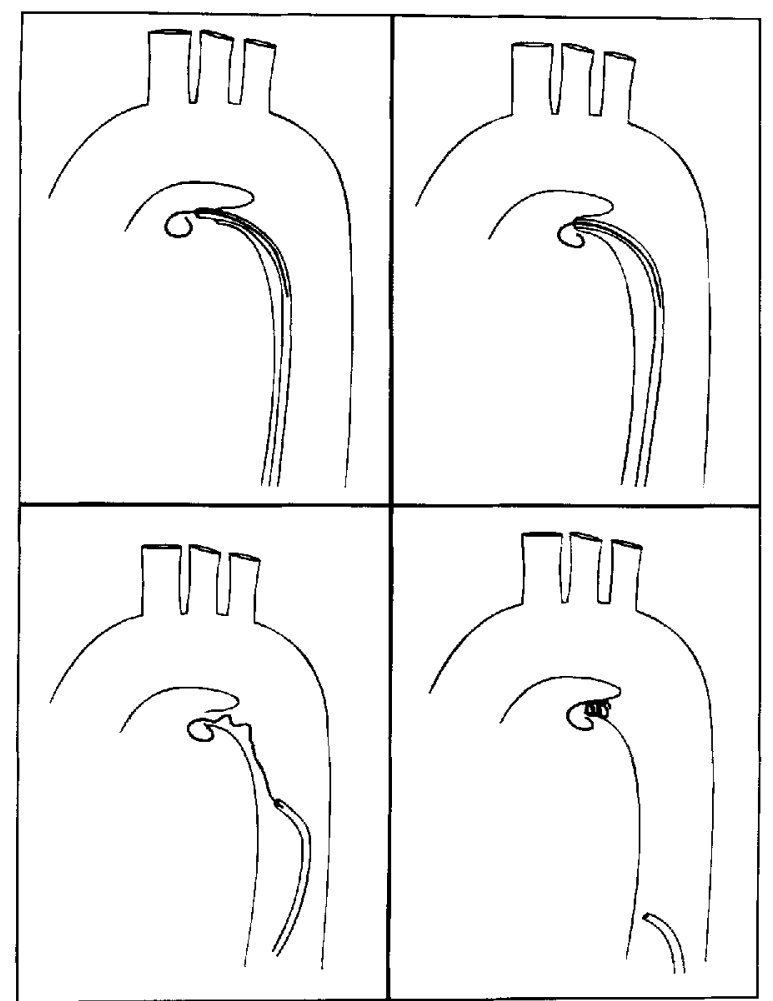

Figure 13. Transarterial method of PDA coil occlusion. With the tip of a 4-5Fr end-hole catheter positioned across the ductus, twothirds to one loop of coil is extruded from the catheter (upper left panel). As the delivery catheter is slowly withdrawn toward the aorta, the distal coil loop engages the narrowest portion of the PDA (upper right panel). The catheter is further withdrawn off of the coil, with care taken that the distal loop does not pull through the PDA (lower left panel). When released from the delivery catheter the coil seats itself in the ductus ampulla, where $2-3$ coil loops complete the occlusion (lower right panel).

12 patients $(24 \%)$, but persisted in $9(18 \%), 4$ of whom have undergone a successful second coil occlusion procedure with complete resolution of residual shunting. Survival analysis using the Kaplan-Meier method estimates the 20 -month prevalence of small residual shunts to be $7 \%$ after a single procedure, and $4 \%$ after all occlusion procedures. Thus, occlusion of the restrictive PDA with Gianturco coils is an effective nonsurgical treatment strategy with a late prevalence of small residual shunts that compares quite favorably to other transcatheter occlusion techniques. A more comprehensive discussion of transcatheter therapy for PDA, including coil embolization, is presented by John Moore, M.D. in this issue.
Bleeding Vessels. Embolization therapy for bleeding vessels is a common procedure in vascular interventional radiology. In pediatric cardiology, indications are generally restricted to patients with aortopulmonary collateral vessels related to cyanotic congenital heart disease, pulmonary vascular obstructive disease (Eisenmenger syndrome), or chronic pulmonary disease. ${ }^{25,26}$ In such patients, hemorrhage from an aortopulmonary collateral vessel can lead to hemoptysis (Fig. 14), increasing hypoxemia and even death. Transcatheter embolization of bleeding vessels can involve the use of coils, Gelfoam, or Ivalon particles. Selective and subselective angiography is mandatory to identify the vessel to be embolized, although angiography often fails to demonstrate active bleeding. In the unusual patient in whom a spinal artery arises from an intercostal artery, embolization of the involved intercostal is contraindicated. ${ }^{27}$ As hemorrhage is a relatively uncommon indication for embolization therapy in pediatric cardiology, collaboration with an interventional radiologist is recommended.

\section{Complications of Embolization Therapy}

Transcatheter embolization therapy is generally quite safe in children, but the more common complications are listed in Table 3. Occlusion of the wrong vessel is, of course, a potentially serious event best avoided by selective angiography to precisely define the anatomy prior to embolization. Selective angiography performed through the delivery catheter immediately prior to embolization helps to assure the operator that the embolization material will be delivered to the desired location. Embolization of a coil or device to an undesired location may also occur, particularly with coils that are too small or too large. A coil that is too small for the vessel to be occluded may embolize distally, for example, to a distal branch pulmonary artery. A coil too large may fail to loop within the target vessel, and may protrude or embolize into a proximal vascular structure. If inappropriate coil size is recognized while the coil is still partially within the delivery catheter, the catheter and coil can often be withdrawn through the introducer sheath. If the coil position does not allow its removal by withdrawing the delivery catheter, then the coil can be recovered from the tip of the delivery catheter with a wire snare introduced through a second sheath. ${ }^{28}$ Released coils can gener- 

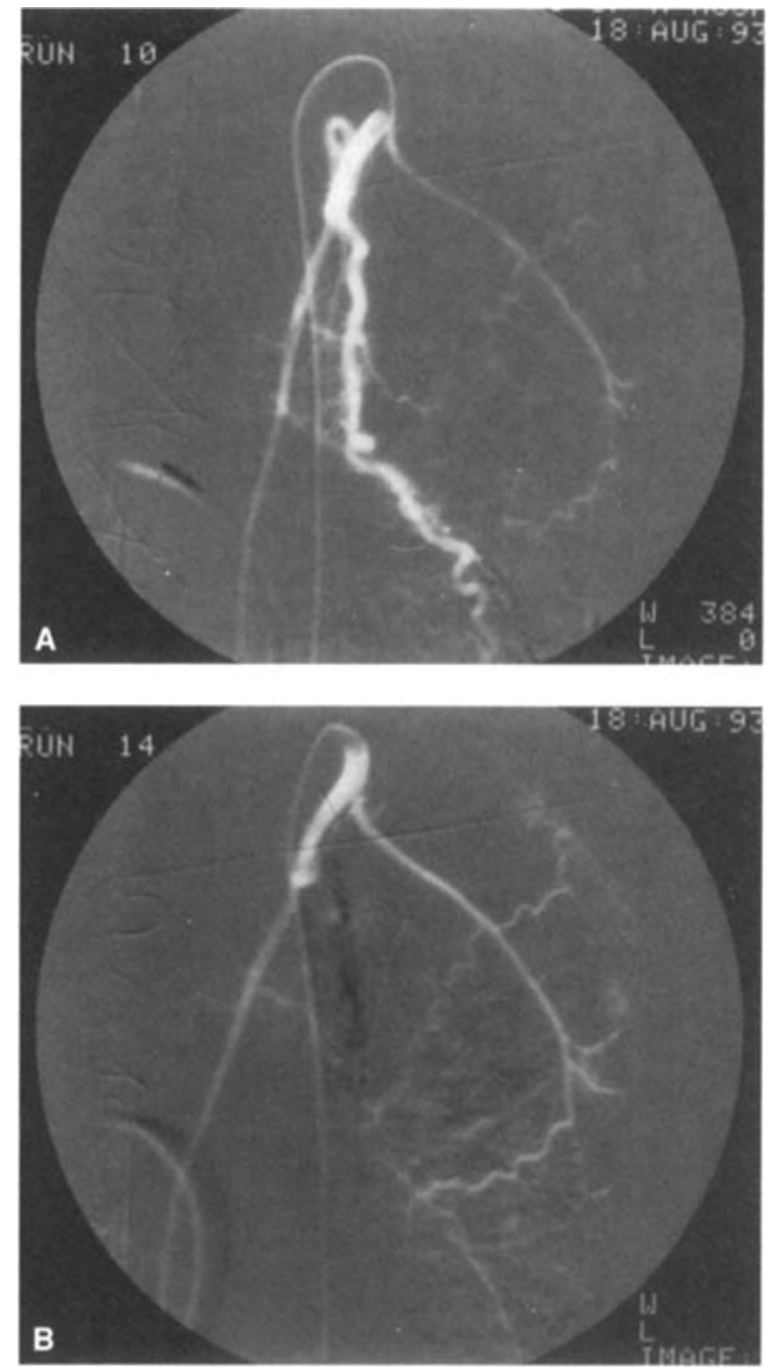

Figure 14. (A) A left internal mammary artery angiogram in a 21year-old woman with hemoptysis following an orthotopic cardiac transplant. There is a dilated and tortuous pericardiophrenic branch which was the source of hemorrhage. (B) The pericardiophrenic branch was selectively cannulated with a Tracker- 18 catheter, and occluded with Ivalon particles and a platinum microcoil. The procedure was performed with collaboration of an interventional vascular radiologist.

Table 3. Complications of Embolization Procedures

Occlusion of wrong vessel

Embolization of cuil or device

Pulmonary infarction

Subtotal vessel oeclusion

Hemolysis

Intection ally be retrieved with a wire snarc or a bioptome introduced through a sheath of appropriate length.

Other complications of embolization procedures include pulmonary infarction, subtotal vessel occlusion, hemolysis, and infection. Pulmonary infarction may occur after occlusion of an aortopulmonary collateral supplying a segment of lung that does not have a dual arterial supply from the central pulmonary vessels; ${ }^{29}$ in our experience, however, this complication is exceedingly rare. Subtotal vessel occlusion is more common in attempted occlusion of large vascular structures and vessels or shunts with high velocity flow. Occlusion may also be incomplete due to use of coils that are too small or too large in diameter. Importantly, small residual shunts noted immediately after coil occlusion of a PDA often resolve spontaneously, a process presumably involving thrombus organization and endothelialization of the coil and its Dacron fibers. Hemolysis has rarely been observed, particularly when high velocity flow persists through or adjacent to an occluding coil or device. ${ }^{7}$ Infection is a small risk after implantation of occluding coils and devices that can be minimized by strict adherence to sterile techniques and the judicious use of prophylactic antibiotics.

\section{Conclusion}

In 1995, embolization therapy provides important definitive or palliative treatment to many paticnts with simple or complex cardiovascular defects. A wide variety of embolization materials and methods is available to the pediatric cardiologist who performs therapeutic catheter procedures. Judicious use of these techniques requires the physician to have facility with the full range of techniques available, an understanding of the anatomy and pathophysiology of the lesion, and knowledge of the physiologicical conscquences and potential complications associated with the catheter intervention. When used properly, transcatheter embolization procedures provide a safe and effective treatment strategy for many paticnts with congenital heart disease.

\section{References}

1. Dawbain G, Lussenhop AJ, Spence WT. Artificial embolization of cerebral arteries, report of use in a case of arteriovenous malformation. JAMA 1960;172:1153-1155. 


\section{BEEKMAN, ET AL.}

2. Gianturco C, Anderson JH, Wallace S. Mechanical devices for arterial occlusion. Am J Roentgenol 1975;124:428-435.

3. Chuany VP, Wallace S, Gianturco C. A new improved coil for tapered-tip catheter for arterial occlusion. Radiology 1980; 135:507-509.

4. White RI, Strandberg JV, Gross GS, et al. Therapeutic embolization with long-term occluding agents and their effects on embolized tissues. Radiology 1977;125:677-687.

5. Johnson WH, Peterson RK, Howland DF, et al. Systemic heparinization does not prevent clot formation in coil embolization. Cathet Cardiovasc Diagn 1990;20:267-270.

6. Castaneda-Zuniga WR, Sanchez R, Amplatz K. Experimental observations on short- and long-term effects of arterial occlusion with Ivalon. Radiology 1978;126:783-785.

7. Perry SB, Radtke W, Fellows KE, et al. Coil embolization to occlude aortopulmonary collateral vessels and shunts in patients with congenital heart disease. JACC 1989;13:100-108.

8. Rothman A, Tong AD. Percutaneous coil embolization of superfluous vascular connections in patients with congenital heart disease. Am Heart J 1993;126:206-213.

9. Lois JF, Gomes AS, Smith DC, et al. Systemic-to-pulmonary collateral vessels and shunts: Treatment with embolization. Radiology 1988;169:671-676.

10. Reidy JF, Jones ODH, Tynan MJ, et al. Embolisation procedures in congenital heart disease. Br Heart J 1985;54: 184-192.

11. Triedman JK, Bridges ND, Mayer JE, et al. Prevalence and risk factors for aortopulmonary collateral vessels after Fontan and bidirectional Glenn procedures. JACC 1993;22:207-215.

12. Gewillig M, Van der Hauwaert L, Daenen W. Transcatheter occlusion of high flow Blalock-Taussig shunts with a detachable balloon. Am J Cardiol 1990;65:1518-1519.

13. Reidy JF, Anjos RT, Qureshi SA, et al. Transcatheter embolization in the treatment of coronary artery fistulae. JACC 1991; 18:187-192.

14. Perry SB, Rome J, Keane JF, et al. Transcatheter closure of coronary artery fistulas. JACC 1992;20:205-209.

15. Latson LA, Forbes TJ, Cheatham JP. Transcatheter coil embolization of a fistula from the posterior descending coronary artery to the right ventricle in a two-year-old child. Am Heart J 1992;124:1624-1626.

16. White RI, Lynch-Nyhan A, Terry P, et al. Pulmonary arteriovenous malformations: Techniques and long-term outcome of embolotherapy. Radiology 1988;169:663-669.
17. Kirsch LF, Sos TA, Engle MA. Successful coil embolization for diffuse, multiple arteriovenous fistulas. Am Heart J 1991; 122:245-248.

18. Routh WD, Keller FS, Cain WS, et al. Transcatheter embolization of a high-flow congenital intrahepatic arterial-portal venous malformation in an infant. J Pediatr Surg 1992;27: 511-514.

19. Lylyk $\mathrm{P}$, Vinuela $\mathrm{F}$, Dion JE, et al. Therapeutic alternatives for vein of Galen vascular malformations. J Neurosurg 1993; 78:438-445.

20. Friedman DM, Verma R, Madrid M, et al. Recent improvement in outcome using transcatheter embolization techniques for neonatal aneurysmal malformations of the vein of Galen. Pediatrics 1993;91:583-586.

21. Cambier PA, Kirby WC, Wortham DC, et al. Percutaneous closure of the small $(<2.5 \mathrm{~mm}$ ) patent ductus arteriosus using coil embolization. Am J Cardiol 1992;69:815-816.

22. Lloyd TR, Fedderly R, Mendelsohn AM, et al. Transcatheter occlusion of patent ductus arteriosus with Gianturco coils. Circulation 1993:88:1412-1420.

23. Moore JW, George L, Kirkpatrick SE, et al. Percutaneous closure of the small patent ductus arteriosus using occluding spring coils. JACC 1994;23:759-765.

24. Shim D, Fedderly RT, Beekman RH, et al. Follow-up after coil occlusion of patent ductus arteriosus. Circulation (In press).

25. Kaufman SL, Kan JS, Mitchell SE, et al. Embolization of systemic to pulmonary artery collaterals in the management of hemoptysis in pulmonary atresia. Am J Cardiol 1986;58: 1130-1132.

26. Fellows KE, Shaw KT, Schuster S, et al. Bronchial artery embolization in cystic fibrosis: Technique and long-term results. J Pediatr 1979;95:959-963.

27. Kardjiev V, Symeonov A, Chankov I. Etiology, pathogenesis and prevention of spinal cord lesions in selective angiography of the bronchial and intercostal arteries. Radiology 1974;112: 81-83.

28. Herrera M, Castaneda-Zuniga WR, Rusnak BW, et al. Removal of partially extended steel coils. Radiology 1982;144: 644-645.

29. Remey-Jardin M, Wattinne L, Remy J. Transcatheter occlusion of pulmonary arterial circulation and collateral supply: Failures, incidents and complications. Radiology 1991;180: $699-705$ 